\title{
Tourism: A Promoter of Human Development
}

\author{
Aniekan Etim Nana \\ http://dx.doi./org/10.4314/ujah.v18i2.11
}

\section{Abstract}

Tourism is a rapidly growing phenomenon and has become one of the largest industries in the world. The impact of tourism varies extremely. On one hand, it plays an important and certainly positive role in the socio-economic and political development in destination countries by, for instance, offering new employment opportunities. It also contributes to a broader cultural and understanding by creating awareness respecting the diversity of cultures and ways of life. On the other hand, it is a tool to create jobs. Tourism has been a major driver. The objective of this paper is to promote the sustainable development of the tourism industry through capacity building of the government in the area of human resource development, improved sectoral planning and governance. The study focuses on empirical investigation of the contribution of the rapidly developing tourism supporting and enhancing infrastructure. Tourism affords huge employment and income generating opportunity. Its impact on bio-physical environment is well acknowledged, hence the emphasis on sustainable tourism and human development. Tourism represent nowadays one of the most dynamic economic sectors, which, despite all the crisis and the unfortunate event of the past, but also in spite of the realities of the global economy nowadays, has demonstrated a tendency towards stable development on the economic, social and environmental planes.

Key words: Tourism, human development, economic development. 


\section{Introduction}

Tourism over the years has proven to be a surprisingly strong and resilient economic activity and a fundamental contributor to economic growth of nations by generating billions of dollars in exports and creating millions of jobs. Acknowledging these facts, many developing and developed countries of today rely on tourism as an option for sustainable development of their nations. Tourism industry has now grown to be the world's largest industries and one of its fastest growing economic sectors. The recent publication of World Travel and Tourism Council (WTTC: 2014), showed that in 2013, travel and tourism's total contribution to the global economy rose to US 17 trillion, about 9.5 per cent of global GDP, not only outpacing the wider economy but also growing faster than other significant sector such as financial and business services, transport and manufacturing and its total contribution to employment was nearly 266 million jobs about 8.9 percent of world employment. The sustained demand for travel and tourism, together with its ability to generate high levels of employment continues to prove the importance and value of the sector as a tool for economic development and job creation.

In sub-Sahara Africa particularly Nigeria, organized tourism date back to 1962 with the creation of Nigeria. Tourism association by group of tourism practitioners in the country. Tourism was officially recognized by government as a potential economic activity in 1976 with the establishment of Nigerian Tourism Board (NTB). In 1992, the Nigerian Tourism Development Corporation (NTDC) was established to replace (NTB) because the latter failed to create any meaningful impact on the country's tourism industry. To strengthen and revitalize the tourism industry, the government in conjunction with United Nations World Tourism Organization 
(UNWTO) and the United Nations Development Programme (UNDP)in 2006 produced a National Tourism Development Master Plan (NTDC), 2006. The master plan produced in three volumes focused on the institutional and capacity strengthening support to tourism sector. And since the tourism activities had gathered momentum in Nigeria.

Tourism today has become one of the engines of growth for Nigeria economy with a contribution of 3.20 percent of national Gross Domestic Product (GDP) and providing 2.70 percent of total employment in 2013 (WTTC, 2014). Tourism industry contribute to GSP, according to World Travel and Tourism Council (WTTC) is envisage to rise by 1.9 percent in growing and it is capable of generating employment and earning large amount of foreign exchange that revealed agriculture and petroleum sector.

Despite tourism's increasing importance in Nigeria economy, the sector has attracted limited attention in terms of empirical research. The objective of this paper is to provide the account of economic contribution of tourism sector to the economy and human development of our Nation. The economy is looking at the providing employment, human development capacity. This paper recommends possible strategies initiative that stakeholders in tourism industry and government can adopt and implement in an effort to rejuvenate the potential of tourism as a veritable tool for economic growth and human development in Nigeria.

\section{Global Importance of Tourism}

Tourism has been recognized as an important social and economic phenomenon at the World Conference on Tourism, held in Manila in 1980s, the importance of tourism and its widespread effects 
were recognized in the Manila Declaration on World Tourism, which stated,

"Tourism is considered an activity essential to the life of nations become of its direct effects on the social, cultural, educational and economic sector of the national societies and on their international relations"

\section{Creating Jobs and Wealth}

a). Travel and Tourism is the world's largest industry and creator of jobs across national and regional economics. WTTC/WEPA research shows than in 2000, Travel and Tourism will generate, directly and indirectly, $11.7 \%$ of GDP and nearly 200 million jobs in the world-wide economy. These figures are forecasted to total $11.7 \%$ and 255 million respectively in 2010 .

b). Jobs generated by Travel and Tourism are spread across the economy in retail construction, manufacturing and telecommunications, as well as directly on Travel and Tourism companies. These jobs employ a large proportion of women, minorities and young people are predominately in small and medium sized companies, and offer good training and transferability. Tourism can also be one of the most effective drivers for the development of regional economics. These patterns apply to both developed and emerging economics.

\section{Contributing to Sustainable Development}

c). The 1992 United Nations Conference on Environmental and Development (UNCED), the Rio Earth Summit, identified Travel and Tourism as one of the key sector of the economy which could make a positive contribution to achieving sustainable development. The earth summit lead to the adoption of Agenda 21, a comprehension program of action 
adopted by 182 governments to provide a global blueprint for achieving sustainable development. Travel and Tourism is the first industry sector to have launched an industry-specific action plan based on Agenda 21.

d). Travel and Tourism is able to contribute to development which is economically, ecologically and socially sustainable, because it:

1. Has less impact on natural resources and the environment that most other industries.

2. Is based on enjoyment and appreciation of Local culture, built heritage, and natural environment, as such that the industry has a direct and powerful motivation to protect these asserts.

3. Can play a positive part in increasing consumer commitment to sustainable development principles through its unparalleled consumer distribution channels and

4. Provides an economic incentives to conserve natural environments and habitats which might otherwise be allocated to more environmentally damaging land channels, and

5. Provide an economic incentive to conserve natural environments and habitats which might otherwise be allocated to more environmentally damaging land used, thereby, helping to maintain Bio-diversity.

6. There are numerous examples of where Travel and Tourism is acting as a catalyst for conservation and improvement of the environment and maintenance of local diversity and culture.

\section{The Importance of Tourism in Nigeria}

The extent to which tourism contributes to the socio-economic and political development of any country is still a subject of debate. Arguably, tourism stimulates the exchange of educational, 
recreational and cultural values in Nigeria. As mass tourists travel to distant place, they bring with their own value system and learn the ways of life of Nigerians. As visitor's travels to Nigeria to stay, they seek to meet and understand the different cultures and backgrounds of the various ethnics groups. As they meet with their host, an exchange of educational cultural ideas takes place. Hence, they travel help to widen the horizon and appreciate other people's culture. Tourism is a great economic force in Nigeria. Tourism analysts and scholars argue that tourism is a catalyst to economic development. It is a potential source of income generation especially, as foreign exchange. The receipts from international tourism are venerable sources of earnings for Nigeria (Okey, 39, Okpolo, 42). Explorers or visitors spending can generate further income for both private and public sectors through the income multipliers - effect. It encourages the financial flow of funds from developed countries into Nigeria.

Another major benefit of tourism is it capacity to stimulate infrastructural development. Perhaps, the benefits from infrastructural development justified the primary reasons for implementing tourism programmes and activities in most states in Nigeria. Most state governors in Nigeria today, like the former governor of Cross River State, Donald Duke, have undertaken the development of new infrastructures and the improvement of the existing infrastructure such as airports, roads, water supply, electricity, hotels and business village like Tinapa, the Ranch Resort (Obudu Cattle Ranch), and Marina Resort. Tourism stimulates employment creation in Nigeria (Okey,39, Okpolo, 44). The tourism trade is a valuable source of employment, globally (Bhattia, 45). In the case of Nigeria, the development of the new infrastructures provides opportunities for job creation. Indeed, the 
tourism sector and its sub sector employ a large number of people, and provide a wide range of jobs ranging from the unskilled to the highly specialized. The construction of roads, airports or airport maintenance, water supply, electricity, construction and renovation of hotels and their accommodations units create jobs for thousands of workers, both skilled and unskilled, particular in Cross River State, where the then Governor, Donald Duke's government undertook a silent revolution in tourism development.

Tourism is an important medium for promoting interventional goodwill and friendship between Nigeria and other nations of the world. Since tourism is a cultural phenomenon, promoting the varied cultures and the styles, its help to foster regional understanding, cooperation, social education among Nigerians and different regions of the world, especially in Africa.

Besides, there is a general agreement among tourist analysts and scholars that the mass flow of visitors of travellers generates negative social values, globally (Okey,38. Hollousay, 327). In Nigeria, the effect of tourism is obvious as it seems to be promoting commercial sex (Prostitution) and sex with minors, child labour. Tourism induces inflation, racism and organized crime (Okpolo, 47). In all, the cost and benefit of tourism development are obvious in Nigeria. If tourism trade is linked to the development of Nigeria and it very existence depends entirely on adequate peace and tranquility, then we are right to study the constraints and adopt measures to counter them.

\section{Tourism as a Tool for Economic Development in Nigeria}

Tourism is widely acknowledged as an effective tool for socioeconomic development, because of the possible backward and 
forward linkage with the rest sectors of the economy, which allows it to facilitate employment opportunities, income, local economic development, and enhance the quality of life (Hall, 16). However, Hall argues that the extent to which these benefits accrues to a nation crucially depends on local conditions. Furthermore, (Manwa, 26), argues that for tourism to be sustainable the community has to benefit directly from it, this will enable them to protect and conserve the resources upon which it is based. This is further emphasized by Smith, that apart from the type of tourism, the extent to which tourism confers economic benefits on any country also depends on the expectation of the tourists and the host country's ability to provide appropriate and adequate facilities.

Unless economic policies to promote tourism remain a focus in developing countries, tourism will not be a potential source of economic growth (Ekanagake. 61- 63). This has been the problem for the developing countries with inadequate infrastructure generally and tourism supporting infrastructure in particular. There is nowhere the problem of inadequate infrastructure is most pronounced than in Nigeria where the death of infrastructure is compounded by the inability to maintain the few existing ones and replicate infrastructure to areas lacking in amenities usually outside of the capital and major cities. In Nigeria, lack of infrastructures is most pronounced in the rural areas where incidentally most of its tourist sites are also located. Nevertheless, efforts at developing infrastructure to support tourism in Nigeria, paltry as these may be, happen only in the urban area (Briedenham and Wicken, 71 - 79). This is where and how tourism is expected to have its most impact on economic development given the infrastructure and income it can attract to rural Nigeria to spur economic growth (Fayissa, Nsiah and Tadaese, 807 - 818), and development in rural areas and 
the regions (SEPO, 2006). In this regard, tourism can facilitate the replication of infrastructure to the regions and the rural areas of Nigeria, which are usually the area which lack amenities (Hawkins and Mann, 345 - 363).

While tourism presents developing countries like Nigeria with huge opportunities and scope for economic diversification, efforts should be made to manage possible adverse social and environmental impacts. Although the quality of the environment, both natural and man-made, is essential to tourism, this cannot be taken for granted given the complex relationships that exist between tourism and the environment (Mbaiwa, 447-467). Many of these impacts are linked with the construction of general tourism enhancing infrastructure such as roads and airports, and of tourism facilities, including resorts, hotels, restaurants, shop, folk course and marinas to name but a few. The associated environmental problems, according to Glaoutzi and Nijkamp19-23, have consequences for the quality and quality of available resources, which in long run could undermine tourism development.

However, Yasong (84-93), has argued that it is not difficult to mitigate the negative impacts of tourism and clarify associated benefits, and that this can be effectively done through tourism planning. This is particularly the case in order not to undermine the carrying capacity of the biophysical environment where local culture such as local celebration, festivals, dance and folklore amongst others could be subsumed (Godfred and Clarke, 38).

\section{Human Development, an Imperative of Sustainability}

The concept of human development is one of the most use phrases now a days, one to which special attention is granted by all 
specialized bodies, but also by world governments through economic policies that have in view sustainable development as a model for long-term development to the advantage of the present and future generations to is, in fact, the new paradigm of development, in the circumstances in which it has been approved that sustainable development is most often regarded only from an environmental perspective, and not from a biolistic one of individual environment development.

Starting from the idea that development represents a process that reunites the ensemble of elements that contribute to the positive change in the quality of life of individuals and of society, in the case of both material element and intangible ones, the concept of human development demonstrates, through its central element-the "human being"- that development is more than a statistics of the increase of specific economic indicators, that it is a new outlook that peruse the creation of an adequate environment in which the human being should be able to reach one's own development level according to one's interest and desire.

According to the 2011 UNEP Human Development Report "human development is the expansion of people's freedoms and capabilities to lead lives that they values and have reason to value. It is about expanding choices" (UNEP, 2011). Human development is the process of widening opportunities for people. Such a development presupposes the creation of opportunities for individual to choose the values and lifestyles that they consider proper for their existences.

Human development is more than economic development, which in this outlook becomes only a means to widen choice and to 
support the development of personal skills. The philosophy linked with this type of development, announced as early as Aristotle's writings, and adopted by twentieth century writers as a theory of ethics, has imposed itself as a modern field of study, not only with the help of economic or social sciences, but also through the contribution of specialist from other science such as medicine and anthropology. In 1971, Denis Goulet presented the "three basic components of the theory of development: decent life standards through the satisfaction of primary needs of individual (security, food and shelter), self-respect and liberty" (Goulet, 87).

Subsequently, Amartya Sen, Laureata of the noble prize for economics in 1998 for it is contribution to economic development, introduces the term of human development, a concept that has been researched in depth by Mahbubun Haq, who has incorporated it in the conception of the Human Development Index (HDI). Based on this research undertaken by the two economists, in 1990 the Human Development Report was drawn, which has hence forth been reanalyzed and improved every year, constituting one of the main sources of analysis of the real state of nations. The 1991 report clearly stipulated that all researches and all official bodies need to acknowledge that people must be considered both ends in themselves, and objectives of the economic development, and that "development must be constituted around people, not the people around development (UNDP; 1991)".

Human development is appreciated differently from classical theories referring to economic growth, the formation of human capital, the development of human resources, the welfare theory, or that of basic (primary) needs of individuals. 
While economic growth is a necessary but insufficient condition to obtain progress in the field of human development, the theories referring to the formation of human capital and to the development of human resources treat individuals mainly as a resources and not as an end in themselves, focusing on their analysis as tools used in the production of goods and services. Although people represent an essential component of the process of production, they should not be regarded from the perspective of "capital goods", but from that of the end beneficiaries of this process. That is why we may say with certainty that these two theories ignore an important part of human development.

Tourism is considered the economic field that is most compatible with sustainable development especially with human dimension, acting out as a stimulating factor for them through its capacity to"

1. Generate workplace, being a sector that is characterized mostly by human Labour and less by mechanized Labour.

2. Create employment opportunities for both intellectuals and under-skilled people, as it is an industry that grants Labour chances to women and young people, who are usually sun favoured categories in the other economic activities;

3. Contribute to the growth of local and domestic revenues, for both the respective companies and the state and authorities;

4. Contribute to the emergence of new products on the market that are related to the tourist consumption pattern (souvenirs and locals' handwork - sometimes real manufacturing industries such as the pottery industry, local cosmetics industry, car rentals or sport products);

5. Contribute to the diversification of local economy and the growth of connected industries that provide for tourism, through its multiplying effect (transportation, agriculture, 
pisciculture, construction, hotel architecture and design, telecommunication, it etc);

6. Offer special opportunities for the establishment of new companies, especially low - and medium size enterprises (SME), stimulating the local private initiative to activate in the field;

7. Impose and stimulate the development of the general infrastructure: airports, ports, roads, utility services such as the water network and sewerage, energy etc, form which the resident population benefits as well;

8. Bring renewed and acknowledgement to a certain destination, contributing to the creation of a positive image for the area in question;

9. Attract, through the development of the general infrastructure and the creation of a business environment, other activities such as commerce, consultancy, real estate, or even investment in production companies that do not necessarily have a connection with tourism but which finds a dynamic niche that supports development (for instance the Rhodes Isle which, despite being known for the beauty of its scapes, the richness of the cultural sights, the quality of the heliomarine factor, has developed in the last years at a shopping destination, the Isle having over six thousand shops with the most famous brands in the world);

10. Support the activities of preservation and protection measures for the conservation of the natural habitat and scapes, an essential condition for tourism;

11. Raise interest in investment in entertainment amenities (theme parks) relaxation areas - natural parks, green space, promenade spaces, ski slopes, investments in special equipment needed for special sports, urban scapismetc) from which locals can 
benefits as well, but which would not have development otherwise, in the absence of tourism;

12. Facilitate the transfers of technology from the countries or regions that possess "know-how" together with investment and the tourism development of the region;

13. Contribute to the attraction of foreign investors, especially in hotels and specific accommodation, food and entertainment amenities;

14. Improve the educational and cultural levels as well as life standard, leading to the improvement of the quality of life for the locals.

\section{The contribution of Tourism to Human Sustainable Development}

Tourism plays an important part in the economic and social life of numerous countries in the world, contributing to economic growth, fighting of poverty, helping cultural conservation, environmental protection, the creation of a peaceful environment, which are practically all objective on the list of human development. Drawing a general comparison with other sectors, it is clear that tourism holds advantages that are superior to other industries or fields of activities, at least through the capacity infiltrate in various sectors of global economy. These advantages are with researching, more so as they have multiple implications, and not only positive ones, on the human being and on the environment.

\section{Advantages and Disadvantages of Tourism}

Tourism is the act of travel for the purpose of not only recreation, but also the provision of services for this act. It might occupy local services such as entertainment, accommodation and catering for 
tourists. It may seem that tourism brings only benefits, but further consideration shows that it also has disadvantages.

Generally, may countries depend greatly upon travel expenditures by foreigners as a source of taxation and as a source of income for the enterprises? Therefore, the development of tourism is often a strategy to promote a particular region for the purpose of increasing commerce through exporting goods and services. Secondly, it provides direct employment for the people associated with occupations in bars and hotels. Thanks to it, the average standard of living of people increases well and at the same time unemployment is on the decrease. However, tourist cause environmental damage through forest fires, destruction of sand dunes and pollution. Consequently this serves negatively as increased pollution disturbs local residents and also it may discourage tourists from further entering the country. After this, tourist undermines culture by commercializing it and this is often connected with increasing litter, graffiti, vandalism and wisetourists do not always respect traditional culture, which is sad but true.

In general, tourism is an extremely profitable process in loads of countries, especially those in which the process of development continues to depend on this industry because this industry does not require a lot of literacy and also it yields maximum profits with less investment.Tourism is a critical source of income for many countries and it generates income through the consumption of goods and services by tourist, and taxes levied on business in the tourism industry, and the opportunity for employment in the service industries associated with tourism. Some of the services offered by these industries include transportation services, such as 
cruise ships and taxis, accommodation services such as hotels, restaurants, bars and entertainment venues, and other hospitality industry services such as spas and resorts. The tourism requires having some of disposable income, time off from work and other responsibilities, proper transportation and accommodation facilities and legal clearance for travelling. More than all, sufficient health condition during the course of travel is required. There are some countries which have legal limitations on travelling abroad. Any projections of growth in tourism serve as a suggestion of the relative influence that each country will exercise in the future.www.ukessays.com/services/essay-writing-service.php.

\section{Conclusion and Recommendation}

Tourism is only in its incipient stages of development, being treated for now as an effective tool for the generation of currency resources, for the creation of workplaces, for drawing investment and for the promotion of economic power, representing both a basic for economic development and a factor of environmental preservation. Nevertheless, for the future will contribute to it valences that will bear relevance to the human sphere more than to the economic one, which will distinguish it from the rest of the economic sectors and will place it within the category of arts and culture of the domains connected with spiritual welfare. The significant impact of tourism in Nigeria economic justified the necessity of Public intervention; this paper recommends provision of adequate security for both domestic and foreign tourists, tax incentives to hotels and tourism related industries and investment in basic infrastructure such as roads, better airport facilities and good transport system. These will go a long way to ensure stable tourism demand for the country. Nigeria government should allocate development funds to projects that are unique to enhance 
tourism development which will give the country a competitive advantage. The government should also encourage the development of three star hotels and should give the private sectors willing to engage in such project and other tourism development projects incentives such as tax break, pioneer status, land at concessionary rate and existing disincentive such as hotel multiregistration region should be removed.

\author{
Aniekan Etim Nana \\ Methodist Theological Institute \\ Umuahia \\ revaninana2000@gmail.com
}

\title{
Works Cited
}

Bhatia, A. K. International Tourism Management. New Delhi: Sterling Publishers Private Limited, 2002.

Briedenham, J. \&Wickens, E. Tourism Routes as a tool for the Economic Development of Rural Areas - Vibrant Hope or Impossible Dream? Tourism Management(25), 2004.

Ekanayake, M. E. \& Long A. E Tourism Development and Economic Growth in Developing Countries. International Journal of Business and Finance Research. (1), 2012.

Fayissa, B. Nsiah, C \&Tadasse, B. The Impact of Tourism on Economic Growth and Development in Africa. Tourism Economics, (14), 2008.

Glaoutzi, M \&Nijkamp, P. Tourism and Regional Development: New Pathways. Ashgate Publication Ltd, 2006. 
Goulet, Denis. "The Cruel Choice: A new Concept in the Theory of Development". Canada: McClelland and Stewart Ltd, 1971. Godfred, K. \& Clark, J. Tourism Development Hardbook: A Practical approach to Planning and Marketing. Thomson Learning Emea, 2000.

Hall, C. M Pro-poor Tourism: Who Benefits, Perspectives on Tourism and Poverty Reductor. London: Channel view Publication, 2007.

Hawkins, D. \& Mann, S. The World Banks's Role in Tourism Development. Annals of Tourism Research,(34), 2007.

Holloway, J Christopher. The Business of Tourism. England: Pearson Educational Limited. 2001.

Long, P. H Tourism Impacts and Support for Tourism Development in Ha Long Bay, Vietnam: An Examination of Residents Perceptions. Asian Social Sciences 8(8), 2012. Mbaiwa, J. E. The Socio-Economic and Environmental Impacts of Tourism Development on the Ollavango Delta, Northwestern Botswana. Arid Environments, (54), 2003.

Manwa, U. Communities Understanding of Tourists and the Tourism Industry: the Lisotho Higlands water Project. African Journal of Business Management, (62), 2012.

Okpolo, Alex I, and Okpolo Uche P. Tourism in Nigeria. Nsukka: Afro Orbis Publishers Limited, 2002.

Okey, Ovat. O. Tourism and Economic Development in Nigeria: An Empirical Investigation. Global Journal of Social Science.2(1), 2003.

SEPO. Policy Insight: Tourism as a Development Strategy: Senate Economic Planning Office of the Philippines, 2006.

Smith, A. Wealth of Nations Cosimo Classical State Information Technology Agency. (2011a). Retrieved 
fromhttp://www.ondostategov.ng/hole of ashes.htm Accessed on 5 April, 2016.

UNDP “Human Development Report" Published for the United Nations Development Programme, New York: Oxford University Press, 1991.

UNDP - Human Development Report - Sustainability and Equity: A Better Future for all, Published for the United Nations Development programme, New York, 2011.

www.ukessays.com/services/essay-writing-service.php. accessed on 11-05-2016

Yasong, A. W. Resident's Attitudes toward Tourism and Perceived Personal Benefits in a Rural community. Travel research (47), 2008. 